\title{
Ultrastructural study of abnormal spermiogenesis in four hystricognate rodents
}

\author{
R. J. Feito* \\ Departamento de Biologia y Quimica, Universidad de Talca, Casilla 747, Talca, Chile
}

\begin{abstract}
Summary. Spermatids and epididymal spermatozoa from wild burrowing hystricognate rodents were examined. Structural defects affected the acrosome, the nucleus and the tail, and were similar to those found in the developing germ cells and spermatozoa from domestic mammals and man.

The acrosome vesiculation of epididymal spermatozoa from hystricognate rodents might not be necessarily an abnormality and may represent a step in the acrosome reaction. Major abnormalities, such as invagination of the acrosome granule, incorporation of lytic vesicles into the forming acrosome, detachment of the acrosome from the flat surfaces of the nucleus, invagination of the nuclear envelope, and the occurrence of multinucleated and multitailed elements may be caused by a variety of factors, but those related to seasonal reproduction (breeding season) should not be neglected.
\end{abstract}

Keywords: spermatogenesis; ultrastructure; rodent; abnormalities

\section{Introduction}

Abnormal spermatozoa have been described mainly in domestic mammals (Hancock, 1972) and in man (Fawcett, 1975), but are rare in most wild species. It is noteworthy, however, that in the rodent suborder Hystricognata (previously Caviomorpha) misshapen spermatozoa occur frequently.

Jones (1974) has reported primary structural abnormalities and disintegration of the acrosome in spermatozoa from hystricognate rodents maintained in laboratory colonies. Captured animals of some species of Ctenomys (Laguardia \& Gerard, 1975; Feito \& Gallardo, 1982) show a high incidence of abnormal spermatozoa.

The reproductive biology of burrowing hystricognate rodents is far from being completely understood, and the biological significance of sperm abnormalities in these species remains unclear. To contribute to a better understanding of the reproductive biology of hystricognates, as well as to give a wider insight on sperm malformation in mammals in general, $I$ have examined the main ultrastructural abnormalities found in spermatids and in epididymal spermatozoa from the cururo (Spalacopus cyanus), the tunduco (Aconaemys fuscus), the tuco tuco from Tamarugal (Ctenomys fulvus), and the tuco tuco from Maule (Ctenomys maulinus).

\section{Materials and Methods}

The animals were live trapped in Chile at their type localities and classified according to Osgood (1943). Most animals were captured during spring and early summer (September to February). Numbers of animals and average weights were as follows: Spalacopus cyanus, 5 males, average weight $92.5 \mathrm{~g}$; Aconaemys fuscus, 1 male, weight $140 \mathrm{~g}$; Ctenomys fulvus, 3 males, average weight $238 \mathrm{~g}$; Ctenomys maulinus, 4 males, average weight $258.7 \mathrm{~g}$. Males were killed in the laboratory by cervical dislocation or by ether anaesthesia.

Small pieces of about $4 \mathrm{~mm}$ of epididymis and testis were immersed immediately after death in $2 \%$ glutaraldehyde in $0.175 \mathrm{M}$-cacodylate buffer at $\mathrm{pH} 8.0$ and fixed for $3 \mathrm{~h}$ at room temperature (Jones, 1973b). After post-fixation in 1\%

*Present address: Centro de Investigaciones Biológicas, Velázquez 144, 28006 Madrid, Spain. 

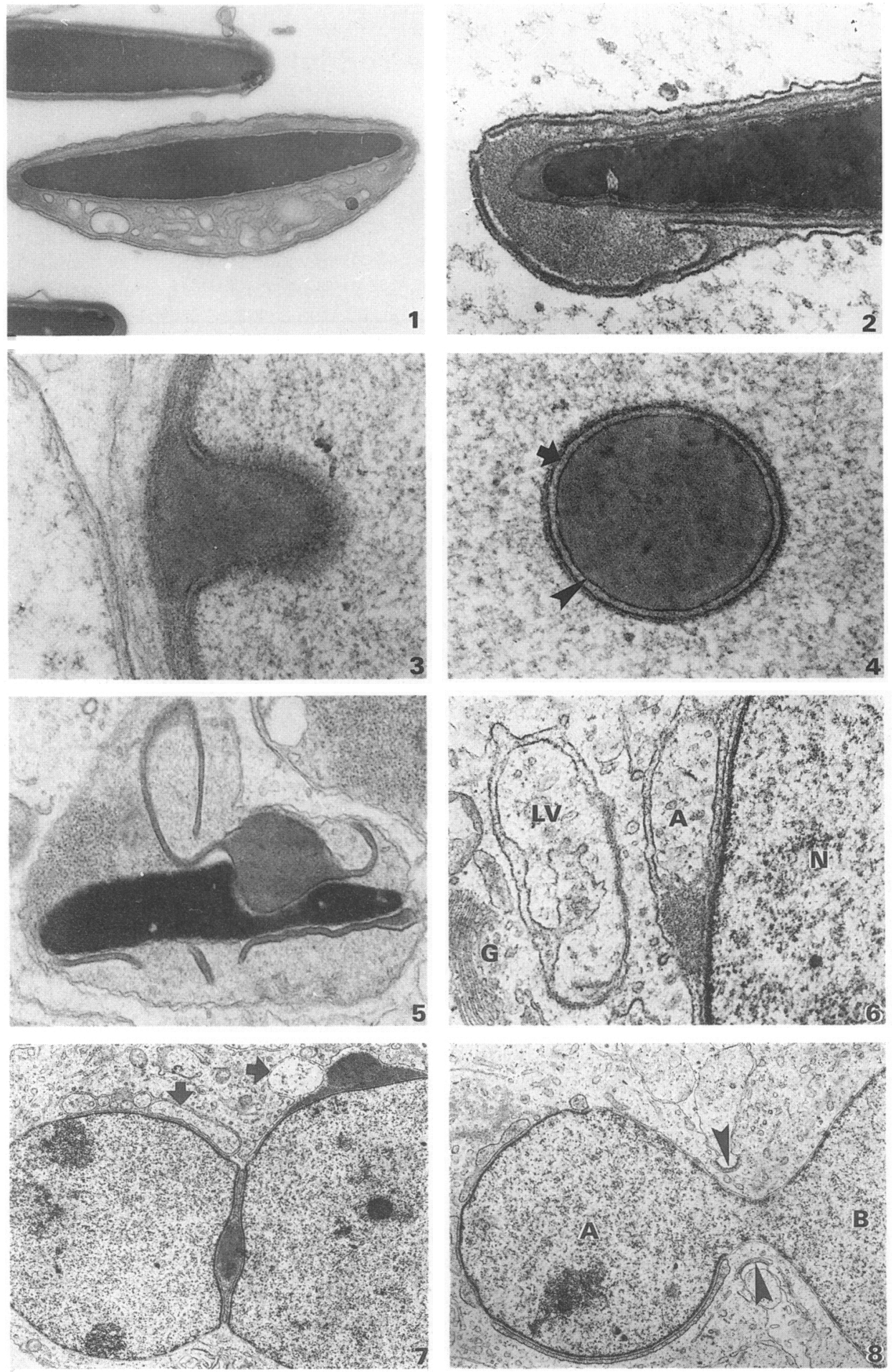
osmium tetroxide in the same buffer specimens were dehydrated in a series of increasing concentrations of acetone and embedded in epoxy-resin according to the method of Spurr (1969).

Thin sections were obtained with an LKB III ultramicrotome, mounted on 300-mesh copper grids, and stained with uranyl acetate and lead citrate by standard methods. Grids were examined in a Philips 300 transmission electron microscope.

\section{Results}

\section{Abnormalities of the acrosome}

In the cauda epididymidis of cururos and tunducos, $24-64 \%$ of spermatozoa had an asymmetric swelling of the apical acrosome containing numerous pleomorphic vesicles (Fig. 1). This swelling was usually accompanied by a decrease in electron density of the acrosomal matrix. Intra-acrosomal vesicles ranged from 75 to $260 \mathrm{~nm}$ in diameter, and resulted from the fusion of the outer acrosomal membrane of the apical segment with the outer acrosomal membrane of the principal segment of the acrosome. The fusion was a consequence of the folding of the apical segment towards the dorsal or the ventral side of the head beneath the plasma membrane (Fig. 2).

In about one-third of late cap-phase spermatids from some specimens of S. cyanus and C. maulinus the acrosomic granule was invaginated, forming a mass protruding into the nucleus (Fig. 3). In transverse sections of the anterior region of spermatids a round acrosomal area limited by the inner acrosomal membrane was seen surrounded by the nuclear envelope (Fig. 4). This area corresponded to the invaginated acrosomal granule. The ring of subacrosomal material surrounding the invaginated acrosomal granule was $35 \mathrm{~nm}$ in thickness.

The acrosome covering the flat surfaces of the nucleus of some elongated spermatids with an invaginated acrosomal granule in cururos was detached and separated from the nuclear envelope (Fig. 5). The acrosome of multinucleate early spermatids found in some specimens of $C$. fulvus was often abnormally formed (Figs 6 and 7). Vesicles resembling autolytic vacuoles were found near the Golgi complex of cap-phase binucleated spermatids. These vesicles would eventually become

Fig. 1. Transverse section of the anterior portion of the head of $A$. fuscus epididymal spermatozoon. Swelling of the acrosome containing vesicles is observed at the ventral region of the head. $\times 23257$.

Fig. 2. Sagittal section of the anterior portion of the head of $S$. cyanus epididymal spermatozoon. The apical segment of the acrosome is folded towards the ventral region of the head. $\times 45220$.

Fig. 3. Sagittal section of a late cap-phase spermatid from $S$. cyanus. The acrosomal granule is invaginated, forming a mass towards the inner part of the nucleus. $\times 30681$.

Fig. 4. Transverse section through the apical region of a late cap phase spermatid from $S$. cyanus. Arrow indicates the nuclear envelope. Arrow head shows the inner acrosomal membrane. $\times 36842$.

Fig. 5. Abnormal elongated spermatid from $S$. cyanus with invaginated apical acrosome. The acrosome is detached from the flat surfaces of the nucleus. $\times 15909$.

Fig. 6. Section through the anterior portion of a $C$. fulvus early spermatid. Vesicles resembling lytic vacuoles (LV) interposed between the Golgi complex (G) and the acrosome (A), N, nucleus. Note the electron-dense matrix of the acrosome displaced downwards by intra-acrosomal cytoplasm. $\times 26146$.

Fig. 7. Binucleated spermatid from $C$. fulvus. Nuclei are fused and sharing the acrosome. Flat arrows show vesicles resembling lytic vacuoles incorporated in the acrosomes. $\times 6827$.

Fig. 8. Early spermatids from $C$. fulvus sharing one nucleus with the shape of an hour-glass. $A$ and $B$ are portions of the nucleus separated by an intercellular bridge (arrow heads) $\times 10054$. 

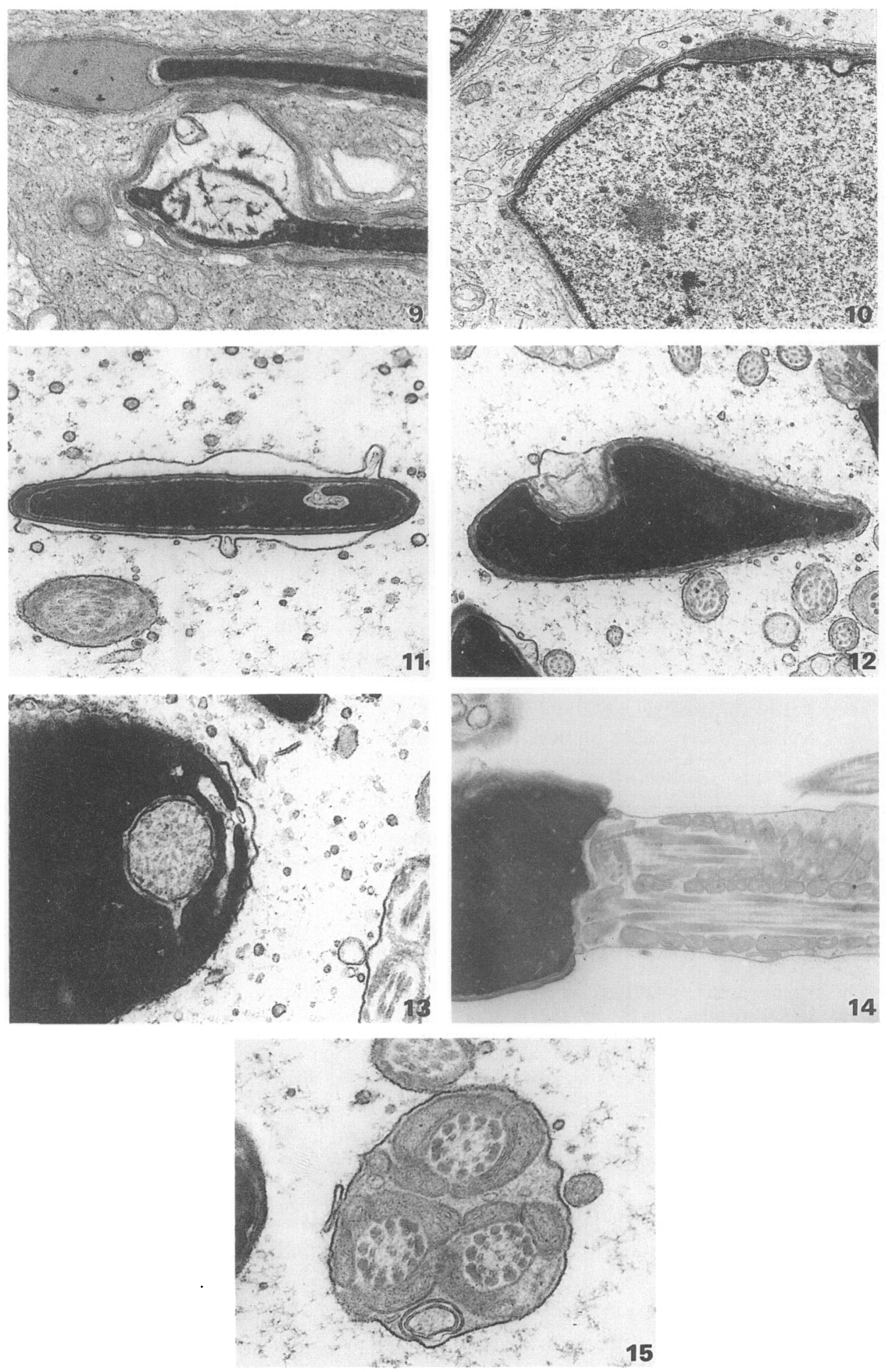
incorporated into the developing acrosome so that the electron-dense matrix of the acrosome is displaced by intra-acrosomal cytoplasm (Fig. 6).

\section{Abnormalities of the nucleus}

Multinucleate early spermatids were frequently found in both species of tuco tucos. Some of the nuclei from these spermatids were fused and sharing the acrosome (Fig. 7). Early spermatids connected by intercellular bridges and sharing the nucleus were observed in $C$. fulvus (Fig. 8). The nucleus was constricted by intercellular bridges and had the shape of an hour-glass (Fig. 8).

Chromatin degradation had occurred in localized and expanded regions of the nucleus of elongated spermatids in some specimens of $C$. maulinus. In these expanded regions of the nucleus the chromatin formed a loose net of electron-dense filaments (Fig. 9). The nuclear envelope of some elongating spermatids of $C$. fulvus showed several invaginations, particularly beneath the acrosome (Fig. 10). Invaginations of the nuclear envelope were also noticed in about $20 \%$ of epididymal spermatozoa from S. cyanus (Fig. 11). Huge vacuoles and vesicles occurred in the nucleus of spermatozoa from the epididymis of some specimens of $S$. cyanus. These structures were often filled with whorls of membranes (Fig. 12) or with fine granular material (Fig. 13).

\section{Abnormalities of the tail}

Biflagellar epididymal spermatozoa were observed in samples of all 4 species, but particularly in $S$. cyanus and $A$. fuscus. Longitudinal sections showed tails arising from two implantation fossae in one head (Fig. 14). Cross-sections of 2, 3 or 4 axonemes enclosed within a single plasma membrane also occurred (Fig. 15).

\section{Discussion}

Vesiculation of the acrosome has been observed in spermatozoa from several mammals and apparently it occurs during the transit of spermatozoa through the epididymis (Jones, 1973a, 1974, 1975). In the bull and the boar this defect is considered to be a cause of sterility and is genetically determined (Hancock, 1972). The decrease in electron density of the acrosome corresponds most

Fig. 9. Sagittal section of $C$. maulinus late spermatids. A net of electron-dense filaments is seen in the expanded region of the nucleus. $\times 23850$.

Fig. 10. Elongating spermatid from $C$. fulvus showing invaginations of the nuclear envelope beneath the acrosome. $\times 11037$.

Fig. 11. Transverse section of the head of a $S$. cyanus epididymal spermatozoon. Invagination of the nuclear envelope is observed. $\times 23060$.

Fig. 12. Epididymal spermatozoon from $S$. cyanus showing an intranuclear vacuole filled with membranes. $\times 14515$.

Fig. 13. Epididymal spermatozoon from $S$. cyanus showing an intranuclear vacuole filled with fine granular material. $\times 20271$.

Fig. 14. Sagittal section of the neck region of a bicaudate epididymal spermatozoon from $A$. fuscus. Tails arise from two implantation fossae. $\times 19053$.

Fig. 15. Cross section at midpiece level of three axonemes enclosed within a single plasma membrane in a $S$. cyanus epididymal spermatozoon. Note the cytoplasm surrounding tails. $\times 33900$. 
probably to the matrix dispersal that is necessary before the folding of the apical segment and loosening of the outer acrosomal membrane (Harrison et al., 1982).

The ultrastructural origin of vesicles found in the acrosome swelling of spermatozoa from $S$. cyanus and $A$. fuscus is similar to that observed in the boar (Jones, 1973a), the bull (Cran \& Dott, 1976), and other hystricognate rodents (Jones, 1974). The participation of the outer acrosomal membrane in the constitution of intra-acrosomal vesicles has been cytochemically confirmed (Holt, 1979). Nagae et al. (1986) have demonstrated the occurrence of intra-acrosomal vesicles bounded by outer acrosomal membrane during the acrosome reaction of human spermatozoa incubated in vitro, and Cummins et al. (1988) have found them during the acrosome reaction of spermatozoa from the grey-headed flying fox (Pteropus poliocephalus). The formation of hybrid vesicles during the acrosome reaction therefore does not seem to be a universal phenomenon, since species-specific differences have been noted (Toepfer-Petersen et al., 1985).

Jones (1975) has indicated that, although the percentage of impaired spermatozoa is high in some hystricognate rodents, it does not seem to reduce fertility, and there is evidence that spermatozoa undergoing acrosomal vesiculation in the boar and the ram maintain their fertilizing ability. Hence, for the time being it is difficult to be certain whether intra-acrosomal vesicles observed in epididymal spermatozoa from hystricognate rodents correspond to abnormal structures or their formation represents a step in a premature acrosome reaction.

Invagination of the acrosomal granule in early spermatids of $S$. cyanus and $C$. maulinus may be caused by an alteration of the acrosome shaping and probably arises when the nuclear material has not yet started the condensation process (Feito, 1988). Separation of the acrosome from the nucleus, and nuclear vacuoles filled with pleomorphic material, have been observed in spermatids (Holstein \& Schirren, 1979) and in ejaculated spermatozoa (Semczuk, 1976; Bartoov et al., 1980) from man. These phenomena probably arise during early spermiogenesis.

Holstein \& Schirren (1979) have described interposing vesicles between the nucleus and the acrosome in abnormal early human spermatids. Vesicular inclusions have been also noticed in the developing acrosome of spermatids from sterile mutants in the mouse (Hunt \& Johnson, 1971). The incorporation of autolytic vacuoles into the acrosome of early spermatids in $C$. fulvus may be a related mechanism.

Invaginations of the nuclear envelope have been observed in bull and boar spermatozoa (McCosker, 1969; Hancock, 1972). Courtens et al. (1980) reported invaginations of the nuclear envelope in spermatids of bulls after peritesticular injection of an alkylating agent. The nuclear envelope also invaginates in spermatids of insects after irradiation with cobalt 60 (Sotelo \& Wettstein, 1969). This abnormality seems therefore to be associated with an acute degenerative process (McCosker, 1969).

Multinucleated spermatids have been also observed in pink-eyed sterile mutants in the mouse (Hunt \& Johnson, 1971), and frequently in human seminiferous tubules (Holstein \& Schirren, 1979; Holstein \& Eckman, 1986). Multinucleated spermatids may result from a separation of the elements forming intercellular bridges or by dissolution of plasma membranes of neighbouring germ cells (Holstein \& Eckman, 1986).

In association with oligozoospermia and advanced age in humans, Holstein \& Eckman (1986) have found spermatids sharing one nucleus with the shape of a dumbbell. This abnormality also occurs in insect testes after irradiation (Sotelo \& Wettstein, 1969).

Bartoov et al. (1980) have reported chromatin degradation in human ejaculated spermatozoa. These authors infer that this chromatin disorder would occur after cell maturation at a late stage of differentiation. This is in accordance with what has been noticed in C. maulinus.

Abnormal multiflagellated spermatozoa occur in many animals (Phillips, 1974), and the observation of several cross-sections of sperm tails within a single plasma membrane is frequent in ultrastructural studies (Hancock, 1972). There are a number of possible interpretations of this abnormality (Hunt \& Johnson, 1971; Hancock, 1972; Beatty \& Fechheimer, 1972; Kojima, 1973; Nistal et al., 1977; Bartoov et al., 1980). 
Studies performed in some mammals (Krzanowska, 1974; Mortimer, 1977; Mortimer et al., 1982) indicate that although the female genital tract can act as a filter to most anomalous spermatozoa, it does not prevent some abnormal spermatozoa reaching the site of fertilization. Furthermore, Moore et al. (1970) have shown that, in vivo, abnormal spermatozoa are able to fertilize mouse eggs and produce viable embryos. The fact that not all misshapen spermatozoa are directly related to sterility (Olds, 1971) may partly explain why abnormal forms have not been negatively selected in wild populations of hystricognate rodents.

Environmental factors, including diet and climatic factors, may contribute to the development of abnormal spermatids and spermatozoa in hystricognate rodents. This might also be related to seasonal changes in fertility (breeding season), since seasonal reproduction is an important cause of hormonal imbalance in mammalian wild populations. Degradation of epididymal spermatozoa occurs in the rock hyrax (Procavia capensis) at the two extremes of the mating season (Millar, 1972), and Bedford (1979) has pointed out that some non-scrotal mammals have a clear dependence on androgens for sperm storage in the cauda epididymidis. The species considered in this study, as generally in hystricognate rodents (Contreras \& Bustos-Obregon, 1980), are non-scrotal and therefore seasonality should not be neglected.

None the less, more studies taking into account reproductive seasonality and experimental conditions are needed to elucidate the actual causes of misshapen sperm production in hystricognate rodents, and to clarify whether they act directly on spermatids or through some endocrine pathway.

I am indebted to Dr E. Bustos-Obregon, Dr J. R. Clarke and Dr P. Esponda for critical review of the manuscript; and Dr O. Garrido and Dr B. Morales for some specimens of C. maulinus and of S. cyanus.

This work has been partly supported by Grant PB 023602 from the Direccion General de Investigación Científica y Técnica, Spain to Dr P. Esponda.

\section{References}

Bartoov, B., Eltes, F., Weissenberg, R. \& Lunenfeld, B. (1980) Morphological characterization of abnormal human spermatozoa using transmission electron microscopy. Archs Androl. 5, 305-322.

Beatty, R.A.\& Fechheimer, N.S. (1972) Diploid spermatozoa in rabbit semen and their experimental separation from haploid spermatozoa. Biol. Reprod. 7, 267-277.

Bedford, J.M. (1979) Evolution of sperm maturation and sperm storage functions of the epididymis. In The Spermatozoon, pp. 7-21. Eds D. W. Fawcett \& J. M. Bedford. Urban \& Schwarzenberg, Baltimore.

Contreras, L. \& Bustos-Obregon, E. (1980) Anatomy of reproductive tract in Octodon degus Molina: a nonscrotal rodent. Archs Androl. 4, 115-124.

Courtens, J.L., Amir, D. \& Durand, J. (1980) Abnormal spermiogenesis in bulls treated with ethylene dibromide: an ultrastructural and ultracytochemical study. J. Ultrastruct. Res. 71, 103-115.

Cran, D.G. \& Dott, H.M. (1976) The ultrastructure of knobbed bull spermatozoa. J. Reprod. Fert. 47, 407-408.

Cummins, J.M., Robson, S. K. \& Rouse, G.W. (1988) The acrosome reaction in spermatozoa of the greyheaded flying fox (Pteropus poliocephalus) exposes barbed subacrosomal material. Gamete Res. 21, 11-22.

Fawcett, D.W. (1975) The mammalian spermatozoon. Devl Biol. 44, 394-436.
Feito, R. (1988) Abnormal acrosomal invagination during spermiogenesis in hystricognate rodents. Microsc. Electr. Biol. Cell 12, 67-72.

Feito, R. \& Gallardo, M. (1982) Sperm morphology of the Chilean species of Ctenomys (Octodontidae). $J$. Mammal. 63, 658-661.

Hancock, J.L. (1972) Spermatogenesis and sperm defects. In The Genetics of the Spermatozoon, pp. 121-130. Eds R. A. Beatty \& S. Gluecksohn-Waelsh. University of Edinburgh.

Harrison, R.A.P., Flechon, J.E. \& Brown, C.R. (1982) The location of acrosin and proacrosin in ram spermatozoa. J. Reprod. Fert. 66, 349-358.

Holstein, A.F. \& Schirren, C. (1979) Classification of abnormalities in human spermatids based on recent advances in ultrastructure research on spermatid differentiation. In The Spermatozoon, pp. 341-353. Eds D. W. Fawcett \& J. M. Bedford. Urban \& Schwarzenberg, Baltimore.

Holstein, A.F. \& Eckman, C. (1986) Multinucleated spermatocytes and spermatids in human seminiferous tubules. Andrologia 18, 5-16.

Holt, W.V. (1979) Development and maturation of the mammalian acrosome. A cytochemical study using phosphotungstic acid staining. J. Ultrastruct. Res. 68, $58-71$.

Hunt, D.M. \& Johnson, D.R. (1971) Abnormal spermiogenesis in two pink-eyed sterile mutants in the mouse. J. Embryol. exp. Morph. 26, 111-121. 
Jones, R.C. (1973a) Changes occurring in the head of boar spermatozoa: vesiculation or vacuolation of the acrosome? J. Reprod. Fert. 33, 113-118.

Jones, R.C. (1973b) Preparation of spermatozoa for electron and light microscopy. J. Reprod. Fert. 33, 145-149.

Jones, R.C. (1974) The ultrastructure of spermatozoa from some hystricomorph rodents. In The Functional Anatomy of the Spermatozoon, pp. 251-258. Ed. B. A. Afzelius. Pergamon Press, Oxford.

Jones, R.C. (1975) Fertility and infertility in mammals in relation to sperm structure. In The Biology of the Male Gamete, pp. 343-365. Eds J. G. Duckett \& P. A. Racey. Academic Press, London.

Kojima, Y. (1973) Boar spermatozoa with multiple heads. J. Reprod. Fert. 35, 537-539.

Krzanowska, H. (1974) The passage of abnormal spermatozoa through the uterotubal junction of the mouse. J. Reprod. Fert. 38, 81-90.

Laguardia, A. \& Gerard, G. (1975) Consideraciones sobre la espermatogénesis de Ctenomys torquatus Licht. Rev. Biol. Uruguay 3, 103-110.

McCosker, P.J. (1969) Abnormal spermatozoan chromatin in infertile bulls. J. Reprod. Fert. 18, 363-365.

Millar, R.P. (1972) Degradation of spermatozoa in the epididymis of a seasonal breeding mammal, the rock hyrax, Procavia capensis. J. Reprod. Fert. 30, 447-450.

Moore, D., Oura, C. \& Zamboni, L. (1970) Fertilizing ability of structurally abnormal spermatozoa. Nature, Lond. 227, 79-80.

Mortimer, D. (1977) The survival and transport to the site of fertilization of diploid rabbit spermatozoa. $J$. Reprod. Fert. 51, 99-104.
Mortimer, D., Leslie, E.E., Kelly, R.W. \& Templeton, A.A. (1982) Morphological selection of human spermatozoa in vivo and in vitro. J. Reprod. Fert. 64, 391-399.

Nagae, T., Yanagimachi, R., Srivastava, P.\& Yanagimachi, H. (1986) Acrosome reaction in human spermatozoa. Fert. Steril. 45, 701-707.

Nistal, M., Paniagua, R. \& Herruzo, A. (1977) Multitailed spermatozoa in a case with asthenospermia and teratospermia. Virchow's Arch. B Cell Pathol. 26, $111-118$.

Olds, P.J. (1971) Effect of the T locus on sperm ultrastructure in the house mouse. J. Anat. 109, 31-37.

Osgood, W.H. (1943) The mammals of Chile. Field Mus. Nat. Hist., Zool. Ser. 30, 1-268.

Phillips, D.M. (1974) Spermiogenesis. Academic Press, New York, pp. 1-68.

Semczuk M. (1976) Investigations on the ultrastructure of spermatozoa in chronic alcoholics. Z. mikrosk.-anat. Forsch. 90, 1[13-1117.

Sotelo, J.R. \& Wettstein, R. (1969) Organization of normal chromosomes and post-irradiation changes in meiotic cells. Genetics, Princeton, Suppl. 61, 53-67.

Spurr, A.R. (1969) A low-viscosity epoxy resin embedding medium for electron miscroscopy. J. Ultrastruct. Res. 26, 3!-43.

Toepfer-Petersen, E., Friess, A.E., Sinowatz, F., Biltz, S. \& Schill, W.B. (1985) Immunocytological characterization of the outer acrosomal membrane (OAM) during acrosome reaction in boar. Histochemistry 82, $113-120$.

Received 20 March 1989 